\title{
Visual outcomes following intravitreal bevacizumab and focal laser in diabetic macular edema
}

\author{
Sharma N. ${ }^{1}$ Singh P. ${ }^{2}$, Singh N. ${ }^{3}$, Kumar K. ${ }^{4}$ \\ ${ }^{1}$ Dr. Nupur Sharma, Senior Resident, ${ }^{2}$ Dr. Priti Singh, Assistant Professor, ${ }^{3}$ Dr. Neha Singh, Junior Resident, ${ }^{4}$ Dr. Kavita \\ Kumar, Professor and HOD, all authors are affiliated with Department of Ophthalmology, Gandhi Medical College, \\ Bhopal, Madhya Pradesh, India.
}

Corresponding Author: Dr. Nupur Sharma, Senior Resident, Department of Ophthalmology, Gandhi Medical College, Bhopal, Madhya Pradesh, India. E-mail: nupur17sham@gmail.com

\begin{abstract}
Purpose: The aim of this study was to evaluate the visual outcome and central macular thickness (CMT) after intravitreal injection of bevacizumab followed by focal laser for the treatment of Diabetic Macular Edema (DME). Patients and methods: This is a prospective, observational study. A total of 30 eyes of 30 patients with Diabetic macular edema were included in this study. The following data were recorded at baseline and during the follow-up periods ( $\leq 6$ months): bestcorrected visual acuity (BCVA), slit-lamp biomicroscopy, CMT and intraocular pressure measurement by applanation tonometry. All eyes received intravitreal bevacizumab at a dose of $1.25 \mathrm{mg}$ in $0.05 \mathrm{ml}$ followed by focal laser after 2 weeks. Results: This study included 30 eyes of 30 patients, the mean age of the patient $59.4 \pm 8.5$ years. There were 19 males and 11 females. The mean baseline BCVA in LogMAR was $0.78 \pm 0.23$, and the final mean BCVA at 6 months had improved to $0.45 \pm 0.20$. Significant improvement was seen in all the patients over the study period $(\mathrm{p}<0.001)$. Mean CMT at baseline was $485 \pm 122 \mu \mathrm{m}$, which decreased to a mean of $321 \pm 82 \mu \mathrm{m}$ at the end of the follow-up period (6 months). Conclusion: Primary treatment for DME with intravitreal bevacizumab followed by focal laser results in improvement of vision and reduces CMT. Combined therapy seems to be an effective modality for treatment of DME.
\end{abstract}

Keywords: Diabetic macular edema, Visual acuity, Central macular thickness, Bevacizumab, Optical coherence tomography.

\section{Introduction}

Diabetes mellitus (DM) is a chronic disease affecting the end-organs, including the retina. The sightthreatening complications of Diabetic Retinopathy (DR) are Diabetic Macular Edema (DME), Retinal detachment, Proliferative diabetic retinopathy (PDR), Retinal artery/vein occlusions. The key mediator involved in pathogenesis of DME is vascular endothelial growth factor (VEGF) causing the breakdown of the blood-retinal barrier (BRB) [1]. DME is clinically significant when it fulfils following criteria: 1) Retinal edema located at or within 500 microns of the center of the macula. 2) Hard exudates at or within 500 microns of the center, if associated with thickening of adjacent retina. 3) A zone of thickening larger than 1disc area, if located within 1-disc diameter of the center of the macula. The diagnosis of DME is based on binocular slit-lamp biomicroscopy (SLB), the

Manuscript received: $10^{\text {th }}$ October 2019

Reviewed: $20^{\text {th }}$ October 2019

Author Corrected: $27^{\text {th }}$ October 2019

Accepted for Publication: $31^{\text {st }}$ October 2019 qualitative and quantitative information of retinal structure and thickness offered by optical coherence tomography (OCT) and fundus fluorescein angiography (FFA). DR affects one third of patients with diabetes and the prevalence increases with duration, poor glycaemic control and duration of hypertension (HTN) [2]. The classification of DME, as described by Otani et al. [3]:1) Spongy-like retinal swelling (SE) 2) Cystoid macular edema (CME) 3) Foveal Serous retinal detachment (FSRD).

The Fluorescein Angiography (FA) classification of DME [4]: 1) Focal leakage- localized areas of leakage from micro aneurysms or dilated capillaries. 2) Diffuse leakage- diffuse leakage involving the entire circumference of the fovea. 3) Diffuse cystoid leakagemainly diffuse leakage, but accumulation of the dye within the cystic areas of the macula during the late phase of the angiogram. Due to the complex mechanism underlying DME a comprehensive approach should 


\section{Original Research Article}

address the treatment of the disease by exploring the opportunity of a combined and more effective therapy. Laser treatment limits the vascular leakage and reduces the vision loss by DME. Argon green (514nm) and frequency-doubled Nd:YAG $(532 \mathrm{~nm})$ lasers are the choice in the management of DME [5].

The mechanism of action of grid lasers is by destroying the photoreceptors in the retina and decreasing the oxygen demand, whereas the focal laser targets leaking micro-aneurysms responsible for macular edema [5].
Intra-vitreal Anti-VEGF Therapy: Anti-VEGF therapy are very promising in treating DME via inhibition of VEGF.Bevacizumab (BVZ) is a humanized monoclonal antibody that competitively inhibits all iso-forms of the VEGF-A [6]. BVZ was approved for treatment of colon cancer. It is used widely as off-label treatment for macular edema and neo-vascular age related macular degeneration [7]. This study is aimed to evaluate the visual outcome and CMT after intravitreal bevacizumab (IVB) in combination with focal laser for the treatment of DME.

\section{Methodology}

Study site: The study was conducted in a tertiary eye care centre in southern India.

Study population: All patients with diabetic macular edema attending retina out-patient department.

Period of study: November 2015 to October 2016.

Study design: A prospective, observational study.

Sample size: 30 eyes of patients attending the retina OPD and fulfilling the inclusion and exclusion criteria.

Sampling technique: Systematic random sampling.

Sampling justification: Based on outcome variables BCVA (Log MAR) for the purpose of sample size calculations, Atul Kumar et al [8] in a clinical study with 90\% statistical power, 5\% level of significance, the sample size of 30 patients is adequate to detect the minimum difference of BCVA (Log MAR) of 0.244 (SD: 0.36).

Sample size calculation formula:

$\mathrm{n}=\mathrm{t} 2 \times \mathrm{p}(1-\mathrm{p}) / \mathrm{m} 2$

$\mathrm{n}=$ required sample size

$\mathrm{t}=$ confidence level of $95 \%$ (standard value of 1.96 )

$\mathrm{p}=$ expected frequency of the factor under study $(1.9 \%)$

$\mathrm{m}=$ margin of error of $5 \%$ (standard value of 0.05 )

$\mathrm{n}=1.962 \times 0.019(1-0.019) / 0.052=29$

Contingency: The sample is further increased by $5 \%$ to account for contingencies such as non-response or recording error.

$n+5 \%$ of $n=29+(5 \%$ of 29$)=30$ sample

Randomization: Not any

\section{Inclusion criteria:}

1. All newly detected cases of diabetic macular edema

\section{Exclusion criteria}

1. Patient with proliferative diabetic retinopathy

2. Prior treatment with lasers

3. Other associated retinopathy

4. Evidence of vitreo-retinal traction

5. Evidence of taut posterior hyaloids

6. Patient with a history of recent cataract surgery.

7. Presence of significant media opacities like cataract, corneal opacities.

8. Prior treatment with intravitreal drugs 


\section{Original Research Article}

Data collection: After enrolment, patients were interviewed for the demographic data such as age, sex, occupation. Patients were asked about the complaints and detailed history was taken regarding the presenting illness. All the findings were documented in a predesigned and pretested proforma.

After obtaining clearance from the Ethical Committee, written informed consent of the patients were obtained for the procedure after discussion of the risks and benefits and the patients were made aware of the follow up. All patients were examined at baseline and $1^{\text {st }}, 3^{\text {rd }}$, and $6^{\text {th }}$ month after the first treatment.

At each visit, examination included:

- Best-corrected visual acuity (BCVA) using LogMAR chart

- Anterior Chamber Examination with Slit Lamp biomicroscopy (Topcon SL 1E, Topcon Corp, Japan),

- Intraocular pressure (IOP) measurement (Goldman's applanation tonometer)

- Fundus examination +90 D Slit Lamp biomicroscopy. (Topcon SL 1E. Topcon corp)

- Evaluation of central macular thickness (CMT) by Optical coherence tomography (OCT) (Cirrus HD OCT 4000 Carl Zeiss; Meditec, Dublin, CA)

The patients included in the study had the following 3 patterns as on OCT: [3]

1. Spongy macular edema

2. Cystoid macular edema

3. Associated foveal serous detachment with a spongy or cystoid edema

Study intervention: (1) IVB injection: The eyes were anesthetized with topical drops of proparacaine $0.5 \%$, sterilized with povidone-iodine solution 5\% for the conjunctival sac and 10\% for the lids, and then bevacizumab (Avastin; Roche Genentech Inc., South San Francisco, California, USA) at a dose of $1.25 \mathrm{mg}$ in $0.05 \mathrm{ml}$ was injected using a 27-G needle into the vitreous $3.5-4 \mathrm{~mm}$ behind the limbus through the infero-temporal quadrant of the globe.

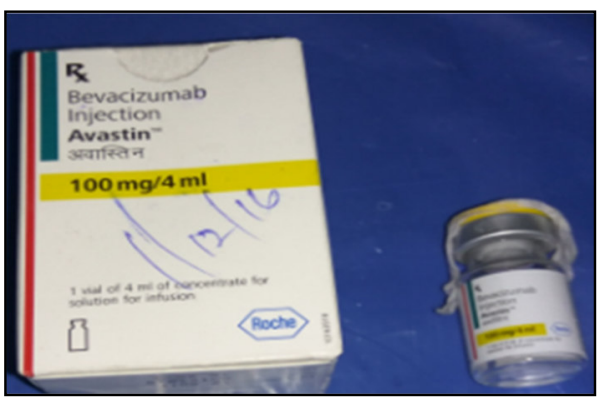

Fig-1: Injection Avastin (Bevacizumab).

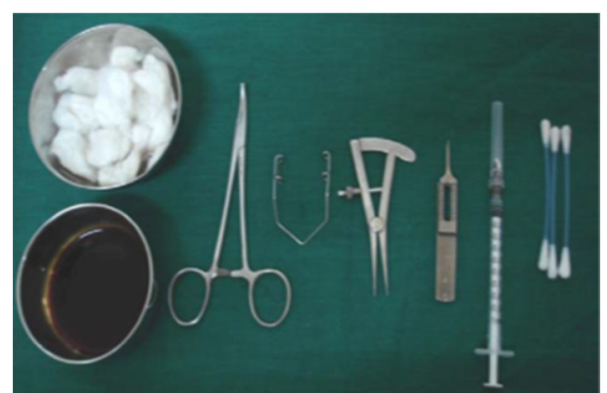

Fig-2: Instruments needed.

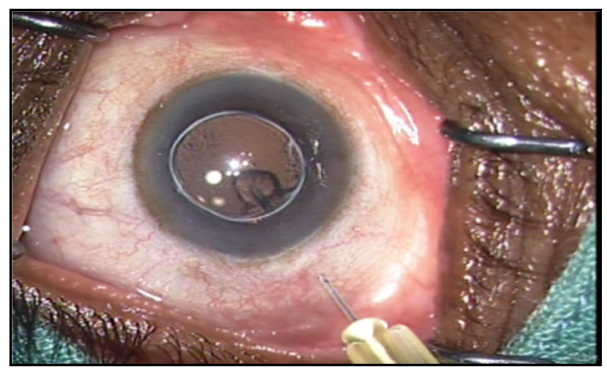

Fig-3: Procedure of injection.

(2) Focal laser treatment: Two weeks after IVB, macular laser treatment was started. The laser treatment was carried out under the following settings: Spot size of 50-100 $\mu \mathrm{m}$, duration of $0.1 \mathrm{~s}$, and power of $80-100 \mathrm{~mW}$. It was applied in a focal pattern according to the treatment map based on FA. 


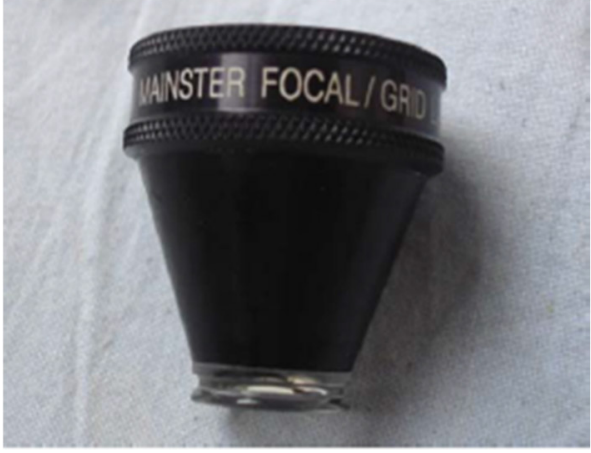

Fig-4: Mainster Focal / Grid Lens.

\section{Original Research Article}

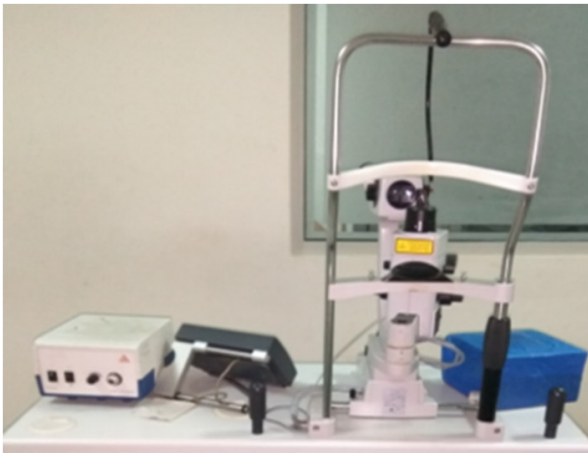

Fig-5: VISULAS 532s.

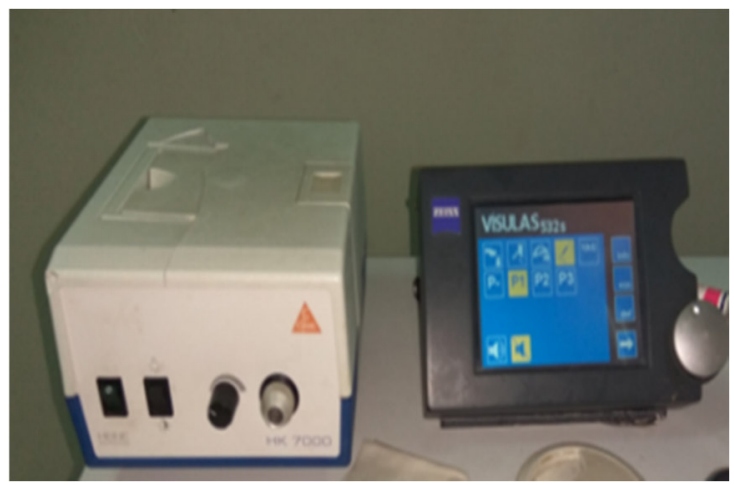

Fig-6: VISULAS 532s.

\section{Results}

A total of 30 eyes of 30 patients with DME who fulfilled the inclusion and exclusion criteria were enrolled in this study. Of the 30 patients, 19 were men and 11 were women. The mean age of the patients was 59.4 \pm 8.5 years (range: 51-60 years).

The evolution of BCVA data is summarized in Fig.7 and Tables 1. An improvement in vision in LogMAR was observed over the study period. The baseline mean BCVA was $0.78 \pm 0.23$ SD which changed to $0.52 \pm 0.16 \mathrm{SD}$ after the first month of treatment, then to $0.40 \pm 0.16$ after 3 months of treatment. A slight deterioration in vision was observed at 6 months follow up to $0.45 \pm 0.20$. Significant improvement is seen all the patients over the study period with no patients with below $1 \log$ MAR $(\mathrm{p}<0.001)$

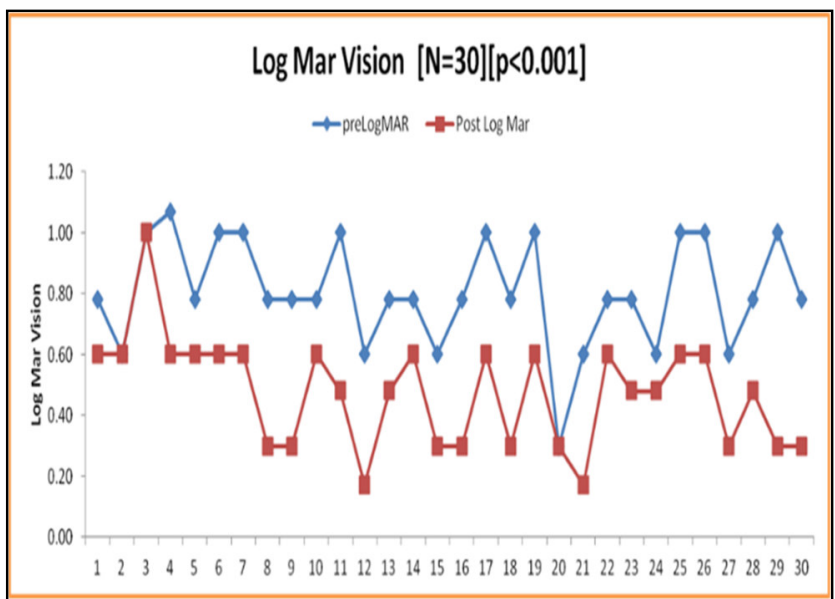

Fig-7: Improvement in vision in LogMAR pre and post procedure. 
Table-1: Mean change in vision over the study time in log MAR

\begin{tabular}{|c|c|c|c|c|c|c|c|}
\hline \multirow{2}{*}{ Study period } & \multirow{2}{*}{ Mean } & \multirow{2}{*}{ SD } & \multicolumn{2}{|c|}{$\begin{array}{c}\text { 95\% CI for } \\
\text { Mean }\end{array}$} & \multirow{2}{*}{ Minimum } & Maximum & Sig \\
\cline { 3 - 6 } & & & Lower & Upper & & & \\
\hline PRE & 0.78 & 0.23 & 0.69 & 0.86 & 0.00 & 1.07 & \\
\hline 1WEEK & 0.65 & 0.19 & 0.58 & 0.72 & 0.17 & 1.00 & \\
\hline 1MONTH & 0.52 & 0.16 & 0.45 & 0.58 & 0.17 & 0.78 & $<0.001$ \\
\hline 3MONTH & 0.40 & 0.16 & 0.34 & 0.46 & 0.00 & 0.60 & \\
\hline 6MONTH & 0.45 & 0.20 & 0.38 & 0.53 & 0.00 & 1.00 & \\
\hline Total & $\mathbf{0 . 5 6}$ & $\mathbf{0 . 2 3}$ & $\mathbf{0 . 5 2}$ & $\mathbf{0 . 6 0}$ & $\mathbf{0 . 0 0}$ & $\mathbf{1 . 0 7}$ & \\
\hline
\end{tabular}

The change in CMT is summarized in Figure 8 and Tables 2. The mean initial CMT was $485+/-122 \mu \mathrm{m}$ and improved to $360+/-88 \mu \mathrm{m}$ after the first month of treatment, then to $314+/-87 \mu \mathrm{m}$ after 3 months of treatment and reached $321+/-$ $82 \mu \mathrm{m}$ at the 6-month follow-up. Following the procedure, a statistically significant reduction in central macular thickness $(\mathrm{p}<0.001)$ was noted.

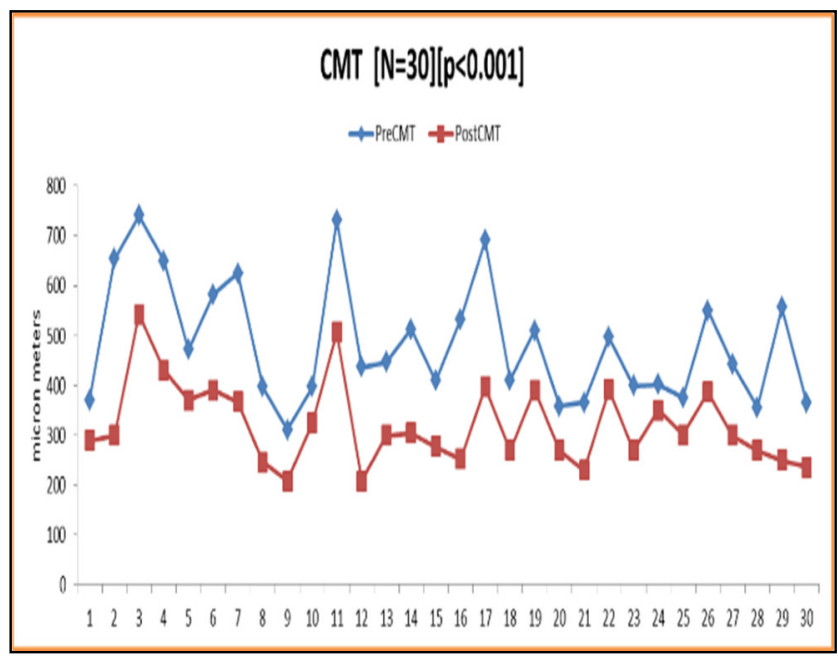

Fig-8: Average change of CMT with time (before and after intervention on follow up visits).

Table-2: Correlation of CMT in various patterns of edema.

\begin{tabular}{|c|c|c|c|c|c|c|c|}
\hline \multirow{2}{*}{$\begin{array}{l}\text { Study } \\
\text { Period }\end{array}$} & \multirow[b]{2}{*}{ Mean } & \multirow[b]{2}{*}{ SD } & \multicolumn{2}{|c|}{ 95\% CI for Mean } & \multirow[b]{2}{*}{ Minimum } & \multirow[b]{2}{*}{ Maximum } & \multirow[b]{2}{*}{ Sig } \\
\hline & & & Lower & Upper & & & \\
\hline PRE & 485 & 122 & 439 & 530 & 310 & 740 & \\
\hline 1WEEK & 439 & 121 & 394 & 484 & 310 & 738 & \\
\hline 1MONTH & 360 & 88 & 327 & 393 & 247 & 587 & $<0.001$ \\
\hline 3MONTH & 314 & 87 & 281 & 346 & 209 & 542 & \\
\hline $6 \mathrm{MONTH}$ & 321 & 82 & 290 & 352 & 208 & 542 & \\
\hline Total & 384 & 121 & 364 & 403 & 208 & 740 & \\
\hline
\end{tabular}

Figure 9 shows that after the procedure, the average CMT reduced from baseline from week 1 till 3 months with a corresponding improvement in vision, after which the average CMT increased between 3 months to 6 months with a corresponding drop in vision noticed in this period. The change in macular thickness positively correlated with change in vision $(\mathrm{r}=+0.787)(\mathrm{p}<0.05)$. 


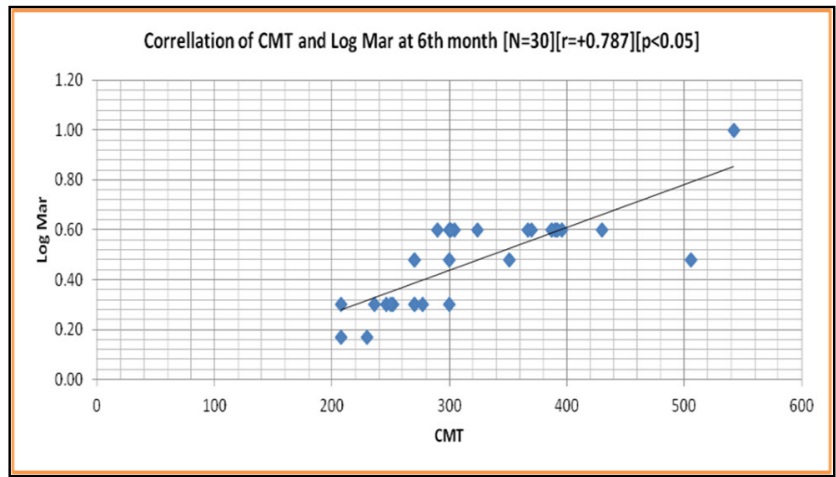

Fig-9: Correlation between average reduction in CMT and Vision.

Figure 10 showed that the mean IOP at baseline was $17.7 \pm 3$. The change in IOP there was an increase in mean IOP at 1 week follow-up was $20.2 \pm 3$ but over subsequent follow-up the IOP was maintained within normal limits. There was no significant increase at the end of follow up period. $(\mathrm{p}>0.05)$.

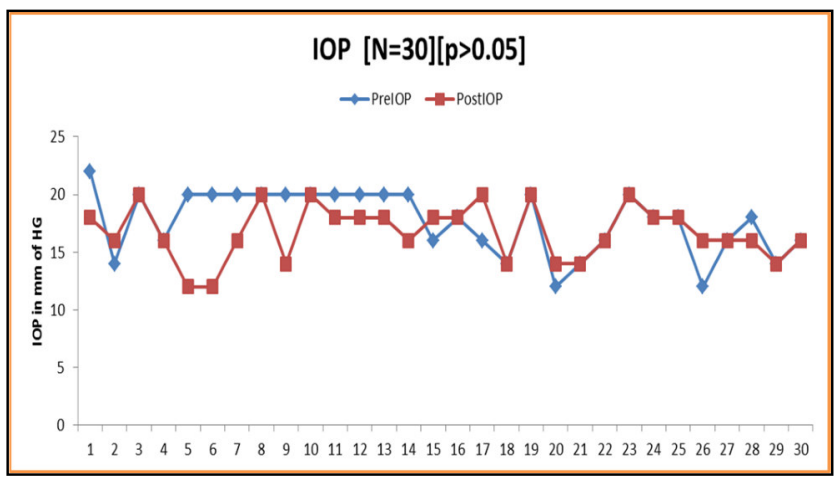

Fig-10: Average Change in intraocular pressure with time (before and after intervention on follow up visits) - By Applanation Tonometry

\section{Discussion}

The aim of the treatment of DME is to prevent deterioration of vision and also improve it. Lasers are gold standard treatment for treating macular edema [9]. ETDRS demonstrated that early laser treatment of macula decreases the frequency of vision loss by $50 \%$ in diabetic patients with macular edema, compared to untreated controls.

Half of the patients with poor vision initially demonstrated improvement in vision at 3-year followup [10]. In focal laser spots are applied over leaking microaneurysm which stops the leakage and reduces macular edema and in grid laser spots are applied over RPE over the areas of diffuse leakage, which increases the reuptake of edema by the RPE pump [11]. Laser Photocoagulation (LPC) also reduces edema by causing destruction of photoreceptor and reducing the oxygen demand of the tissues. Park et al [12] 2004 in their study reported that LPC is gold standard of care in DME but usually only stabilizes vision, slowly over a period of time. Whereas, an addition of pharmacological agents to laser treatment gives an additional benefit in terms of both VA and patient quality-of-life. An interval of 2 weeks is preferred between, IVB and LPC, as the halflife of bevacizumab in the vitreous is 4.9days and duration of action of about 2 weeks. In the present study, a significant improvement in mean BCVA was observed, from $0.78 \pm 0.23 \operatorname{LogMAR}$ pre procedure to $0.45 \pm 0.20$ LogMAR post procedure $(\mathrm{P}<0.001)$.

The mean CMT decreased significantly from $485 \pm 122$ $\mu \mathrm{m}$ pre procedure to $321 \pm 82 \mu \mathrm{m}$ post procedure which was significantly less $(p<0.001)$. Scott et al [7] 2007 conducted a multicenter clinical trial on 78 eyes with DME treated with at least one injection of IVB (56/78 eyes) at a dose of $1.25 \mathrm{mg}$ on 6 months follow up there was a statistically significant improvement in BCVA; $43(55 \%)$ eyes improved ( 0 or more ETDRS lines) and CMT decreased significantly from 387 to $276 \mu \mathrm{m}$ at the end of follow-up. In the present study at 1 week follow up visual improvement was $0.65 \pm 0.19$, at 1 month VA was improved to $0.52 \pm 0.16$, at 3 months it was 
$0.40 \pm 0.16$. At 6 months a slight decrease in VA was seen being $0.45 \pm 0.20$ LogMAR. But the overall improvement in VA was statistically significant at the end of 6 months. Lee et al. [13], in their study comparing treatment with BVZ in 90 eyes with treatment with a combination of BVZ and macular LPC 38 eyes for DME, with a follow up of 6 months. They reported an improvement in vision and reduction in CMT without significant difference between the two groups. They demonstrated faster improvement in vision which was maintained until the end of the follow-up period in the combination group. In 2010, Otani et al [14] reported that spectral-domain optical coherence tomography showed that the integrity of the external limiting membrane and inner and outer segments of the photoreceptors more strongly correlates with best-corrected visual acuity when compared with central subfield thickness in diabetic macular edema.

Solaiman KA et a [15] in their study on 62 eyes of 48 patients evaluated the efficacy of intravitreal injection IVB followed by modified grid laser photocoagulation (MGP) versus each alone as a primary treatment of diffuse diabetic macular edema.

The changes in CMT, BCVA, changes in fluorescein angiography leakage were compared. This study concluded that combined therapy with IVB and sequential MGP 3 weeks later appeared to be superior to MGP or IVB alone in reducing macular thickening and improving visual acuity. Lee et al [16] compared the efficacy between IVB and combination treatment (IVB and MPC) similar to the present study for treatment of DME. Patient were reviewed until 6 months. VA and CMT were studied on each follow-up.

They observed visual improvement at 1 month follow-up in both the group, but there was no significant improvement in visual acquity on final follow-up in either groups.

They reported significant decrease in CMT in both the groups at 6 months. Ahmed H Mohamed [6] in 2016 evaluated the visual outcome and CMT after IVB in conjunction with MLP for the treatment DME. They studied 32 eyes of 27 patients were included in this study and received IVB at a dose of $1.25 \mathrm{mg}$ in $0.05 \mathrm{ml}$ 2 weeks before MLP, which was applied in a focal or grid pattern. The mean baseline BCVA was $0.29 \pm 0.11$ decimal Snellen's equivalent, and the final mean BCVA was $0.38 \pm 0.13$. Analysis of the final BCVA revealed that $15(47 \%)$ eyes improved by two or more lines of BCVA, $16(50 \%)$ eyes remained stable, and one (3\%) eye lost one line of BCVA. Mean CMT at baseline was

\section{Original Research Article}

$625.18 \pm 82.88 \mu \mathrm{m}$, which decreased to a mean of $283.46 \pm 22.47 \mu \mathrm{m}$ at the end of 6 months. They also concluded that combined therapy seems to be an effective modality for treatment of DME. The mean intraocular pressure was $17.7 \pm 3 \mathrm{mmHg}$ at baseline. The mean IOP at 1 week showed an elevation $20.2 \pm-3$ and at 3 months and it was reduced to the baseline levels $(16.9 \pm 2)$ at 3 months follow up. The change in IOP was not significant at the end of follow up period of 6 months ( $>00.05)$. Kahook MY et al [17] reported a probable cause of elevation of IOP is due to clogging of the trabecular meshwork leading to outflow obstruction by high molecular weight aggregates. The present study showed that combined treatment with IVB and focal laser is effective in reducing the retinal thickness measured by OCT and significantly improving visual acuity.

It can be concluded that IVB and focal laser is safe and effective procedure for the management DME. The limitations of this study are small sample size, short postoperative follow-up period. The present study had not studied the postoperative and long-term complications of the intravitreal bevacizumab and focal laser along with the impact of other associated systemic illness like hypertension or hyperlipedimia on outcome of DME. The present study had also not compared the current findings with patients receiving only intravitreal bevacizumab and only focal laser for diabetic macular edema at our hospital.

\section{Conclusion}

Combined intravitreal bevacizumab and focal laser appears to be a helpful option for improving or stabilizing BCVA in DME patients.

\section{What the study adds to the existing knowledge?}

The present study showed that IVB followed by focal laser is effective in enabling visual improvement and reduction in CMT in most cases. The present study adds that combined therapy with IVB and focal laser is safe and effective procedure for the management of DME.

The duration of diabetes, preoperative BCVA and preoperative CMT are important prognostic factors.

\section{Author's contribution}

Dr. Nupur Sharma: Concept, Study design

Dr. Priti Singh: Manuscript writing

Dr. Neha Singh: Statistical analysis

Dr. Kavita Kumar: Manuscript writing 
Original Research Article

Funding: No funding sources

Conflict of interest: None declared

Ethical approval: This study was approved by the Institutional Ethics Committee

\section{References}

1. Mathew C, Yunirakasiwi A, Sanjay S. Updates in the management of diabetic macular edema. J Diabetes Res. 2015; 2015:794036. doi: 10.1155/2015/794036. Epub 2015 Apr 23

2. Ding J, Wong TY. Current epidemiology of diabetic retinopathy and diabetic macular edema.Curr Diab Rep. 2012;12(4):346-354.doi:10.1007/s1 1892-0120283-6

3. Otani T, Kishi S, Maruyama Y. Patterns of diabetic macular edema with optical coherence tomography. Am J Ophthalmol.1999;127(6):688-693.doi: 10.1016/s00029394(99) 00033-1

4. Wu L, Fernandez-Loaiza P, Sauma J, HernandezBogantes E, Masis M. Classification of diabetic retinopathy and diabetic macular edema. World J Diab. 2013;4(6):290-294. doi: 10.4239/wjd.v4.i6.290.

5.Romero-Aroca P, Reyes-Torres J, Baget-Bernaldiz M, Blasco-Suñe C. Laser treatment for diabetic macular edema inthe21st century.Curr Diabetes Rev.2014;10 (2) :100-112.doi:10.2174/15733998106661404021230 26

6. Mohamed AH. Intravitreal bevacizumab plus macular laser photocoagulation for treatment of diabetic macular edema. Delta J Ophthalmol. 2016;17(2):97-101. doi: 10. 4103/1110-9173.189073.

7. Diabetic Retinopathy Clinical Research Network1, Scott IU, Edwards AR, Beck RW, Bressler NM, Chan $\mathrm{CK}$, et al. A phase II randomized clinical trial of intravitreal bevacizumab for diabetic macular edema. Ophthalmol. 2007;114(10):1860-1867. Epub 2007 Aug 15. doi: 10.1016/j.ophtha.2007.05.062.

8. Kumar A, Sinha S. Intravitreal bevacizumab (Avastin) treatment of diffuse diabetic macular edema in an Indian population. Indian J Ophthalmol. 2007; 55(6):451-455. doi: 10.4103/0301-4738.36481.

9. Park YG, Kim EY, Roh YJ. Laser-based strategies to treat diabetic macular edema: history and new promising therapies. J Ophthalmol. 2014;2014:769213. doi: 10.1155/2014/769213. Epub 2014 Sep 22.

10. Photocoagulation for diabetic macular edema. Early Treatment Diabetic Retinopathy Study report number 1. Early Treatment Diabetic Retinopathy Study research group. Arch Ophthalmol. 1985;103(12):1796-1806. doi:10.1001/archopht.1985.01050120030015.

11. Bandello F, Lanzetta P, Menchini U. When and how to do a grid laser for diabetic macular edema. Doc Ophthalmol. 1999;97(3-4):415-419. doi: 10.1023/a: 1002499920673

12. Lee HY, Lee SY, Park JS. Comparison of photocoagulation with combined intravitreal triamcinolone for diabetic macular edema. Korean $\mathrm{J}$ Ophthalmol. 2009;23(3):153-158.doi:10.3341/kjo. 2009. 23.3. 153. Epub 2009 Sep 8.

13.Lee SJ, Kim ET, Moon YS. Intravitreal bevacizumab alone versus combined with macular photocoagulation in diabetic macular edema. Korean $\mathrm{J}$ Ophthalmol. 2011;25(5):299-304. doi: 10.3341/kjo.2011.25.5.299. Epub 2011 Sep 20.

14.Otani T, Yamaguchi Y, Kishi S. Correlation between visual acuity and foveal microstructural changes in diabetic macular edema. Retina. 2010;30(5):774-780. doi: 10.1097/IAE.0b013e3181c2e0d6.

15.Solaiman KA, Diab MM, Abo-Elenin M. Intravitreal bevacizumab and/or macular photocoagulation as a primary treatment for diffuse diabetic macular edema. Retina. 2010;30(10):1638-1645. doi: 10.1097/IAE.0b 013e 3181eled07.

16.Lee SJ, Kim ET, Moon YS. Intravitreal bevacizumab alone versus combined with macular photocoagulation in diabetic macular edema. Korean J Ophthalmol. 2011;25(5):299-304. doi: 10.3341/kjo.2011.25.5.299. Epub 2011 Sep 20.

17. Kahook MY, Kimura AE, Wong LJ, Ammar DA, Maycotte MA, Mandava N. Sustained elevation in intraocular pressure associated with intravitreal bevacizumab injections. Ophthalmic Surg Lasers Imaging. 2009;40(3):293-295. doi: 10.3928/1542887720090430-12.

\section{How to cite this article?}

Sharma N, Singh P, Singh N, Kumar K. Visual outcomes following intravitreal bevacizumab and focal laser in diabetic macular edema. Trop J Ophthalmol Otolaryngol.2019; 4(6):395-402. doi:10.17511/jooo.2019.i06.07 